\title{
An Evalution of the Demographic and Clinical Characterictics of Patients with GM2 Gangliosidosis
}

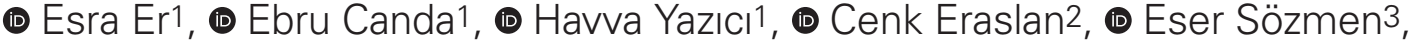 \\ ه Sema Kalkan Uçar1, (® Mahmut Çoker1 \\ ${ }^{1}$ Ege University Faculty of Medicine, Department of Pediatrics Metabolism and Nutrition, Izmir, Turkey \\ 2Ege University Faculty of Medicine, Department of Radiology, Izmir, Turkey \\ ${ }^{3}$ Ege University Faculty of Medicine, Department of Medical Biochemistry, Izmir, Turkey
}

\begin{abstract}
Aim: The purpose of our study is to submit the demographic, phenotypic and age at diagnosis characteristics of children with GM2 gangliosidosis.

Materials and Methods: Patients with GM2 gangliosidosis who were referred to Ege University Faculty of Medicine, Department of Pediatrics, Division of Pediatric Nutrition and Metabolism between January 2004 and December 2016, were included in this study. Diagnosis was confirmed by determining the level of serum $\beta$-hexosaminidase activity and genetic mutation analysis. The demographic and clinical features are reported for 8 patients with Tay-Sachs disease (TSD) and 6 with Sandhoff disease.

Results: The mean age at diagnosis was 18.2 months (range 4-48 months) and 14.5 months (range 8-36 months) for patients with TSD or Sandhoff disease respectively. The initial and main complaint in $100 \%$ of the patients were neurological disorders, such as developmental delay, developmental regression or both; seizures and macrocephaly. None of the patients exhibited evidence of organomegaly. Cranial magnetic resonance imaging results were normal in $36 \%$ of the cases, $55 \%$ of the cases had bilateral thalami involvement presenting as T2 hyperintensity especially at the posterior thalami and $9 \%$ of cases had myelination delay.

Conclusion: GM2 gangliosidosis disease should be considered for children with developmental regression and/or delay. To prevent a delay in diagnosis, $\beta$-hexosaminidase activity in serum and genetic mutation analysis should be undertaken in suspected cases. Curative gene therapy may be available in the future.

Keywords: GM2 gangliosidosis, hexoaminidase, Tay-Sachs disease, Sandhoff disease
\end{abstract}

\section{Introduction}

GM2 gangliosidoses including Tay-Sachs disease [TSD, Online Mendelian Inheritance in Man (OMIM) 272800], Sandhoff disease (SD, OMIM 268800) and GM2 activator protein deficiency (GM2; OMIM 272750) are rare lysosomal storage disorders of the sphingolipid metabolism due to an autosomal recessive inheritance. These disorders are characterized by a disrupted lysosomal defect of glycosphingolipid, accumulating in the organelle with the respective glycoconjugates. GM2 gangliosides occur due to the enzymatic presentation of impaired activity of hydrolase b-hexosaminidase or rarely from defects in GM2 activator protein. The incidence of TSD and SD is common in some populations, Ashkenazi Jewish or individuals of French Canadian decent (1-3).

A hereditary defect in the hexosaminidase A-subunit gene (HEXA, chromosome 15) or hexosaminidase B-subunit gene (HEXB, chromosome 5) results in the absence of (HEX, E.C.3.2.1.52) isoenzymes. 
TSD and its variants arise from mutations in the HEXA gene and are associated with deficient HEXA activity but normal HEXB activity. SD and its variants are caused by mutations in the HEXB gene and are associated with a deficiency of both HEXA and HEXB activity. GM2 gangliosidosis, $A B$ variant, is a rare form of GM2 gangliosidosis resulting from a lack of GM2 activator protein, it is associated with autosomal recessive mutations in GM2A. Defects in any of these three genes result in an excessive accumulation of GM2 and related glycolipids, mostly in lysosomes in neural cells, and form a rare neurodegenerative disorder (4-8).

Some people with SD are clinically indistinguishable except for visceral and skeletal indications $(9,10)$. These disorders may occur at almost any age with neurodegeneration which progresses at a variable rate. Patients with the classical onset of the disease suffer an accumulation in the retinal ganglion cells leading to the "cherry-red spot"; these children succumb to prompt neurodegeneration and pass away in early childhood. Less frequently, juvenile-onset forms present with progressive cerebellar dysfunction, dementia and spasticity. Rarely, adult-onset variants occur; but the symptoms of disease present in childhood (11-15). No curative therapy is available for GM2 gangliosidosis. Seizures generally respond to standard treatment.

Fourteen patients with GM2 gangliosidoses, referred to Ege University Faculty of Medicine, Department of Pediatrics, Division of Inborn Error of Metabolism, were included in our study. We evaluated age, gender, medical background, developmental state, clinical features and the neuroimaging findings of these individuals.

\section{Materials and Methods}

The medical records of 14 children with GM2 gangliosidosis who were referred to Ege University Faculty of Medicine, Department of Paediatrics, Division of Inborn Error of Metabolism between January 2004 and December 2016 were retrospectively evaluated.

The hospital records of the patients included in our study were reviewed. We assessed age, gender, past medical background, developmental state and the neuroimaging findings of these individuals. Their clinical manifestations and neuroimaging findings were the factors leading to their diagnosis which was confirmed by analysis of $\beta$-hexosaminidase activity in their serum.

Descriptive methods were used to analyze data and statistical testing was not performed. Written consent was obtained from all parents who participated in this survey.

\section{Statistical Analysis}

The quantitative analysis of patients is presented as means. The qualitative characteristics are summarized as a frequency distribution.

\section{Results}

In our study, 14 individuals ( 3 female, 11 male) diagnosed with GM2 gangliosidosis [8 (57\%) with TSD, 6 (43\%) with $\mathrm{SD}]$ were included. Consanguinity was reported in 10 $(71.4 \%)$ individuals. Four patients $(28.5 \%)$ had a positive family history. The first symptoms of these GM2 diseases were noticed at the mean age of 8.6 months (range 4-14 months) for patients with TSD and 8.5 months (range 4-13 months) for patients with SD.

With respect to their developmental evaluation, 71\% of patients demonstrated developmental regression. The mean age of developmental regression was 12.3 months. Developmental regression occurred at a mean age of 9 months (range 4-16 months) and 17.25 months (range 8-22 months) for patients with TSD and SD respectively.

Neurologic features present singularly or with other properties, such as developmental delay or regression in 11 of $14(79 \%)$, strabismus or perceived visual degradation in two of $14(14 \%)$, hyperacusis with extreme startle in 2 of 14 $(14 \%)$ and seizures in 9 of 14 (64\%) [mean age of 14 months (range 4-28 months)] children with GM2 gangliosidosis.

None of the children with GM2 gangliosidosis disease achieved independent walking. Thirteen (93\%) patients had combined axial hypotonia and limb spasticity. Retinal storage leading to a visible cherry-red spot was reported in 12 of 14 $(86 \%)$ individuals.

Two of the patients had a distinct facial appearance, namely a protuberant forehead, a depressed nasal bridge and hypertelorism. Weight in 3 of 14 (21\%) patients less than the $3^{\text {rd }}$ percentile and height in 4 of $14(29 \%)$ patients less than the $3^{\text {rd }}$ percentile.

Three patients showed macrocephaly. None of the patients exhibited any evidence of organomegaly. One patient had rocker bottom foot, a valgus and equinus deformity of the foot (Figure 1). In laboratory data, three patients had increased levels of aspartate aminotransferase and alanine aminotransferase.

The neuroimaging data revealed that $36 \%$ of the patients had normal neuroimaging results; $55 \%$ of patients had bilateral thalami presenting as T2 hyperintensity of the

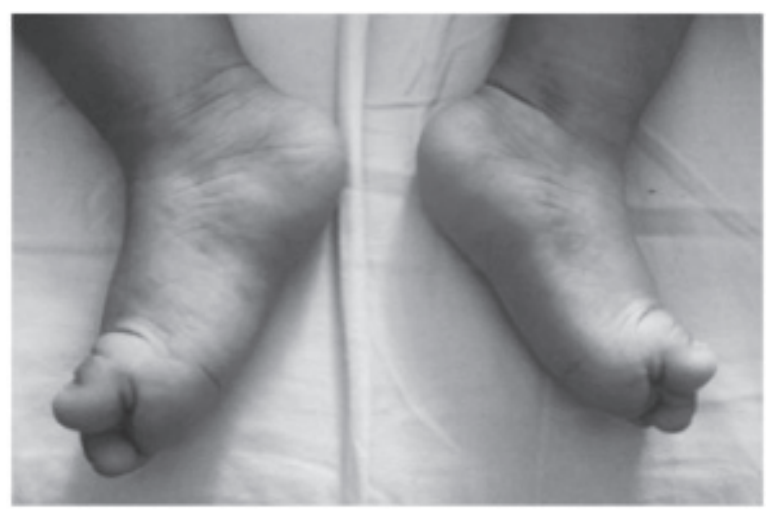

Figure 1. Rocker bottom foot, valgus and equinus deformity of the foot is demonstrated 
posterior thalami; $9 \%$ of the patients showed myelination delay.

The mean age at diagnosis, determined by $\beta$-hexosaminidase activities, was 14.5 months (range 8-36 months) and 18.2 months (range 4-48 months) for individuals with TSD and SD respectively. A delay of 4.6 months (range 1-13 months) and 10.6 months (range 1-40 months) from symptom onset to diagnosis was seen in TSD and SD respectively (overall average of 8 months).

The $\beta$-hexosaminidase $A$ enzyme activity, the total $\beta$-hexosaminidase enzyme activity and mutation analysis detected in our Tay-Sachs and Sandhoff patients are shown in Tables I and II respectively.

Death was recorded in 10 of the 14 patients $(71.5 \%)$ and occurred at a mean age of 29.4 months (range 19-45 months). The cause of death was pneumonia and/or respiratory failure in $8(57 \%)$ children. For the remaining 6 patients $(43 \%)$ in the study, the cause of death is unknown.

\section{Discussion}

GM2 gangliosidoses are caused by a lysosomal storage of ganglioside GM2 and related gangliosphingolipids in neurons and glial cells. TSD and SD are a result of lysosomal $\beta$-HEXA deficiencies caused by gene mutations in HEXA and HEXB, respectively encoding the $\alpha$ - and $\beta$-subunits of HEXA ( $\alpha \beta$ heterodimer) and are associated with an excessive accumulation of GM2 in the brain, which leads to neurological symptoms. The clinical phenotype of the classic infantile form of GM2 gangliosidosis is characterized by normal early development followed by developmental regression, progressive weakness, exaggerated startle, vision loss with cherry-red spots and seizures (8).

In this study, although the number of male patients is higher than female patients, there were no significant gender related differences.

The mean age at diagnosis was 14.5 months (range 8-36 months) and 18.2 months (range 4-48 months) for patients with TSD and SD respectively. Similar to our study, Gort et al. (16) showed that the age at diagnosis range for TSD patients was between 7-36 months and the age at diagnosis range for SD patients was between 7-21 months.

With respect to their developmental evaluation, 71\% of individuals showed developmental regression. The mean age of developmental regression was 12.3 months. According to an Iranian paediatric case series based on 18 patients with GM2 gangiosidosis, $66 \%$ of patients presented developmental regression and the mean age of developmental regression was 15 months, which is similar to our findings (17).

Multiple seizures types were noted, for example generalized convulsive seizures and myoclonic seizures. Gort et al. (16) mentioned that seizures occurred in individuals with infantile-onset disease at an average age of 15.1 months (range 4-30 months), which is similar to our study.

\begin{tabular}{|l|l|l|l|}
\hline Table I. Genotype and total hexosaminidase levels in Sandhoff disease patients & Allel 2 & Total HEX level in serum \\
\hline Patient & Allel 1 & - & $512 \mathrm{nmol} / \mathrm{h} / \mathrm{mg}(4500-17000)$ \\
\hline 1 & - & - & $9.14 \mathrm{nmol} / \mathrm{h} / \mathrm{mg} \mathrm{protein} \mathrm{(1097-1341)}$ \\
\hline 2 & - & - & $15 \mathrm{nmol} / \mathrm{h} / \mathrm{mg} \mathrm{protein} \mathrm{(600-2675)}$ \\
\hline 3 & - & c.995>C (p.F332S) & $48.09 \mathrm{nmol} / \mathrm{h} / \mathrm{mg} \mathrm{protein} \mathrm{(1223 \pm 273)}$ \\
\hline 4 & c.995>C (p.F332S) & IVS11+5G $>$ A & $61 \mathrm{nmol} / \mathrm{h} / \mathrm{mg} \mathrm{protein} \mathrm{(1223 \pm 273)}$ \\
\hline 5 & c.156_170del15bp & - & $7.5 \mathrm{nmol} / \mathrm{mL} / \mathrm{h}(104-321)$ \\
\hline 6 & - & & \\
\hline
\end{tabular}

HEX: Hexosaminidase

Table II. Genotype and hexosaminidase A levels in Tay-Sachs disease patients

\begin{tabular}{|l|l|l|l|}
\hline Patient & Allel 1 & Allel 2 & HEXA level in serum \\
\hline 1 & $\begin{array}{l}\text { c.1096_1107del12bp } \\
\text { (p.366_369delYGKG) }\end{array}$ & $\begin{array}{l}\text { c.1096_1107del12bp } \\
\text { (p.366_369delYGKG) }\end{array}$ & $4.79 \mathrm{nmol} / \mathrm{h} / \mathrm{mg}$ protein $(116 \pm 39)$ \\
\hline 2 & - & - & $7.3 \mathrm{umol} / \mathrm{L} / \mathrm{h}(50-250)$ \\
\hline 3 & - & - & $2.23 \mathrm{nmol} / \mathrm{h} / \mathrm{mg}$ protein $(116 \pm 39)$ \\
\hline 4 & c.902 T>G (M301R) & c.902 T>G (M301R) & $2.8 \mathrm{umol} / \mathrm{L} / \mathrm{h}(50-200)$ \\
\hline 5 & c.1099_1110del12bp & $\begin{array}{l}\text { c.1099_1110del12bp } \\
\text { (p.336_369delYGKG) }\end{array}$ & $2.92 \mathrm{nmol} / \mathrm{h} / \mathrm{mg}$ protein $(116 \pm 39)$ \\
\hline 6 & (p.336_369delYGKG) & - & $1.5 \mathrm{nmol} / \mathrm{h} / \mathrm{mg}$ protein $(116 \pm 39)$ \\
\hline 7 & - & c.798G>C (p.W266C) & $1.18 \mathrm{nmol} / \mathrm{h} / \mathrm{mg}$ protein $(116 \pm 39)$ \\
\hline 8 & c.798G>C (p.W266C) & - & $1.3 \mathrm{nmol} / \mathrm{mL} / \mathrm{h}(7-70)$ \\
\hline
\end{tabular}


Typical fundal variations are rare in the juvenile onset variant of the disease, although loss of vision due to optic atrophy and retinitis pigmentosa may occur (12-15). Kokot et al. (18) made appropriate diagnoses of Sandoff and TSD in their individuals based on a prompt eye fundus inspection and the determination of the cherry-red spots in the central area. Cherry-red spots were detected in $88 \%$ of the Iranian paediatric case series, which is similar to our cases (17).

Organomegaly was not determined in any of the patients in our study. Similarly, Barness et al. (19) did not mention organomegaly for individuals diagnosed with SD.

In our study, $36 \%$ of patients had normal neuroimaging results; $55 \%$ of patients had bilateral thalami presenting as T2 hyperintensity of the posterior thalami; $9 \%$ of patients exhibited myelination delay. Yun and Lee (20) mentioned low signal intensity in the thalamus and high signal intensity in the white matter of brain in T2 weighted magnetic resonance imaging.

The large number of the published reports, which are based on single case reports or a small number of cases or alternatively retrospective cross-sectional studies (a clinical data report obtained over a period of time) lack information on the patients' mutations. The correlation between the disease progression and the phenotype of the genotype is speculative since the number of patients is generally low with these diseases. The genetic analysis of one patient revealed c.798G $>C$ in the HEXA gene. This mutation is a novel mutation which causes the disease according to the modelling program. Segregation analysis from parents is planned to be conducted.

In this study, we reported that the mean age at death was 29.4 months (range 19-45 months), pneumonia and/ or respiratory insufficiency was the cause of death for $57 \%$ of the patients, with reason of death unspecified in the remaining $43 \%$ of the children. Smith et al. (21) reported that the mean age at death was 36.3 months (18 months-6years 9 months) and pneumonia/respiratory failure was the cause of death for $58 \%$ of children with $\mathrm{GM} 2$ gangliosidoses.

\section{Study Limitations}

The limitation of the current study is that molecular analysis of all patients cannot be performed.

\section{Conclusion}

GM2 gangliodiosis are rare, but have severe presentation. In order to diagnose earlier, $\beta$-hexosaminidase activity assay should be undertaken when GM2 gangliodiosis are suspected. Currently, curative treatment is not available, however, gene therapy may be the hope that provides clinical improvement. Fundus examination should be evaluated in infants with developmental delay and/or developmental retardation and GM2 gangliosidoisis should be considered in differential diagnosis of patients with cherry-red spot.

\section{Ethics}

Informed Consent: Informed consent was obtained. Peer-review: External and internal peer-reviewed.

\section{Authorship Contributions}

Surgical and Medical Practices: E.E., E.C., H.Y., C.E., E.S., Concept: S.K.U., Design: M.Ç., Data Collection or Processing: E.C., Analysis and Interpretation: H.Y., Literature Search: E.E., Writing: H.Y.

Conflict of Interest: No conflict of interest was declared by the authors.

Financial Disclosure: The authors declared that this study received no financial support.

\section{References}

1. Meikle PJ, Hopwood JJ, Clague AE, et al. Prevalence of lysosomal storage disorders. JAMA 1999;281:249-54.

2. Andermann E, Scriver CR, Wolfe LS, et al. Genetic variants of Tay-Sachs disease: Tay-Sachs disease and Sandhoff's disease in French Canadians, juvenile Tay-Sachs disease in Lebanese Canadians, and a Tay-Sachs screening program in the French- Canadian population. Prog Clin Biol Res 1977;18:161-88

3. Myrianthopoulos N. Some Epidemiological and Genetic Aspects of Tay Sachs Disease. (Academic Press, New York, 1962.).

4. Sandhoff K. The GM2-gangliosidoses and the elucidation of the beta-hexosaminidase system. Adv Genet 2001;44:67-91.

5. Gravel RA, Triggs-Raine BL, Mahuran DJ. Biochemistry and genetics of Tay-Sachs disease. Can J Neurol Sci 1991;18:419-23.

6. Martino S, Cavalieri C, Emiliani C, et al. Restoration of theGM2 ganglioside metabolism in bone marrow derived stromal cells from Tay-Sachs disease animal model. Neurochem Res 2002;27:793-800.

7. Martino S, Emiliani C, Tancini B, et al. Absence of metabolic cross-correction in Tay-Sachs cells:implications for gene therapy. J Biol Chem 2002;277:20177-84.

8. Gravel R, Kaback M, Proia $R$, et al. The GM2 gangliosidosis. In: Scriver CR, Beaudet A, Sly WS, Valle D, eds. The Metabolic and Molecular Basis of Inherited Disease. 8. New York: McGraw-Hill 2001;3827-76.

9. Sandhoff K, Andreae U, Jatzkewitz $H$. Deficient hexozaminidase activity in an exceptional case of TaySachs disease with additional storage of kidney globoside in visceral organs. Life Sci 1968;7:283-8.

10. Krivit W, Desnick RJ, Lee J, et al. Generalized accumulation of neutral glycosphingolipids with GM2 ganglioside accumulation in the brain. Sandhoff disease [variant of TaySachs disease]. Am J Med 1972;52:763-70.

11. JohnsonWG. The clinical spectrum of hexosaminidase deficiency disease. Neurology 1981;31:1453-6.

12. Maegawa G, Stockley T, Tropak M, et al. The natural history of juvenile or subacute GM2 gangliosidosis: 21 new cases and literature review of 134 previously reported. Pediatrics 2006;118:e1550-62.

13. Neudorfer O, Pastores GM, Zeng BJ, Gianutsos J, Zaroff CM, Kolodney EH. Late-onset Tay-Sachs disease: phenotypic characterization and genotypic correlations in 21 affected patients. Genet Med 2005;7:119-23. 
14. Federico A, Palmeri S, Malandrini A, Fabrizi G, Mondelli M, Guazzi GC. The clinical aspects of adult hexosaminidase deficiencies. Dev Neurosci 1991;13:280-7.

15. Gravel RA, Kaback MM, Proia RL, Sandhoff $K$, Suzuki $K$, Suzuki K. The GM2 gangliosidoses. In: Valle D, Beaudet AL, Vogelstein B, Kinsler KW, Antonarakis SE, Ballabio A, editors. The Online Metabolic \& Molecular Bases of Inherited Disease. Scriver's OMMBID. New York: McGraw-Hill, 2010: http://dx.doi.org/10.1036/ommbid.184.

16. Gort L, de Olano N, Macías-Vidal J, Coll MA; Spanish GM2 Working Group. GM2 gangliosidoses in Spain: analysis of the HEXA and HEXB genes in 34 Tay-Sachs and 14 Sandhoff patients. Gene 2012 Sep 10;506:25-30. Epub 2012 Jul 10

17. Karimzadeh $P$, Jafari N, Nejad Biglari H, et al. GM2gangliosidosis (Sandhoff and Tay Sachs disease): Diagnosis and neuroimaging findings (an Iranian pediatric case series). Iran J Child Neurol 2014;8:55-60.

18. Kokot W, Raczyńska K, Krajka-Lauer J, IwaszkiewiczBilikiewicz B, Wierzba J. Sandhoff's and Tay-Sachs disease-based on our own cases. Klin Oczna 2004;106(3 Suppl):5346.

19. Barness LA, Henry K, Kling P, et al. A 7-year old white-male boy withprogressive neurological deterioration. Am J Med Genet 1991;40:271-9.

20. Yun YM, Lee SN. A case refort of Sandhoff disease. Korean J Ophthalmol 2005;19:68-72.

21. Smith NJ, Winstone AM, Stellitano L, Cox TM, Verity CM. GM2 gangliosidosis in a UK study of children with progressive neurodegeneration: 73 cases reviewed. Dev Med Child Neurol 2012;54:176-82. 